\title{
Innovation and System Design
}

\author{
M. Mukherjee
}

\begin{abstract}
Analysis the solution or planning, meeting with the employees, clients, consultants how the product would be better than the competitors. After studying the information we have the choose one of these three option: how can develop the system, how can improve the current system or if any of these two are not possible than leave the system. Planning stage is the preliminary step for a successful system, at first we have to detect the problems how we solve it and what we want to do, the objectives and the resources, required cost etc. System design is the second step in the system. Here a feasibility study is needed to recognize the requirements of the end user's i.e. customers, what are the expectations of them for the system. It is very vital to maintain a strong communication with the customers. Ensure that the finished product can fulfil its required level and its function. Design phases arise after the good understanding with the customer; it defines the elements of a system, the security level and the different types of data which are necessary for the system. A general system design may be complete with pen-paper work. After the designing phase the system required an implementation process. In the phases the system fulfil the customer promises, now the system is ready to running, training may be required or not. This phase may be takes a long time, that's depends on the complexity of the system.
\end{abstract}

\section{Keywords}

Entrepreneurship; Fact finding techniques; Innovation; System analysis; System design.

\section{INTRODUCTION}

In business and production unit management System Analysis and Design (SDA) consider as a process of observation for all arrived and predicted situation with the intention to improve the whole procedures. For the performance and growth of the system including the objectives for achieving profitability, system analysis is a mandatory process. Having gathered all information and all details regarding the target system as much as feasible, now the systems analyst go through it to realize the whole system operation technique, and to try and recognize all the troubles and problems arrives that require to be solve and try to convert difficulties into opportunity [1]. There are interrelationship in designing of product, designing of organization, competitive strategy, processes for learning and managing knowledge, and etc. [2].

Basically a business is a chance of doing something new in the market and with the help of this we can help a lot of people in our society as well as our country. Most large organizations are in fact made up of many sub-systems and sub-modules [3]. Similarly a large process is also made up by many sub process. The processes which are running under sub-modules may refer as sub-systems processes [4]. Each sub-process takes data and information from the main inputs or may be from other processes or from both, by few courses of action or by processing the data the system generates an output. The output may be further used as input by passing it to other next processes, and so on [5]. Looking at a system and its sub-systems we may observed that how efficiently it works. By changing one module the quality of the output are parts may be analysis for future enhancements. Organizations are mainly composite systems that consist of many interconnected and interlocking sub-process and sub-systems. Alteration in any module of the system have both probable and unexpected penalty in other sub-process [6]. The systems need to simulations or computer base analysis and design of different computer based realizations. It may provides a structure for imagine the organizational and ecological issue which work on a sub system or as a whole system. When a computer and other automatic machine are introduced into an organization, different role of the existing workers may affect as a result both the client and organization suffered. Among the optimized peoples are change and improved routine and a sensation of accomplishment with some additional information to enhance their job roles [7]. Among the unexpected penalty might be a possible like lose their employment, decrease the spirits of recruits due to lack of participation and a feeling of demands by end users and organizations due to their lack of technical knowledge to handle the automatic machine or may be for computer illiteracy [8]. The system analyst's responsibility is to take out such kinds of doubts and try to make the whole modernizations successful.

Authors Details:

*M. Mukherjee

IJOAEM, India

e-mail: ijoaem@gmail.com

Subject Category: Management

Sub Category: System Design and Management 


\section{INNOVATION \& ENTREPRENEURSHIP}

The innovation is basically a tool of the entrepreneurship, by the mean of which they exploit changes as a chance for a many business and services. The innovation is basically capable of getting learned and capable of being practiced. Entrepreneurship is basically a man who develops his own business and that business is new in the market and helpful for the people of society [9]. It can be utilized by policy makers not only to identify the key policy issues but also to set policy goals is one of the major thing in the entrepreneurship an entrepreneur is the one who implement his idea in the market and makes his company successful and established in the market and they need to apply the innovation in the business for the better improvement [10]. "Activities" in innovation systems are the determinants of the development and diffusion of innovations. Examples are R\&D, provision of organizations and institutions, financing of innovations, incubation, etc. These activities are partly performed by private organizations and partly by public organizations, the latter performing tasks that constitute innovation policy. As a basis for innovation policy, the problems (failures) in the systems must be identified [11].

As now we already know about the entrepreneurship and innovation now we are going to think about the uses of the innovation in entrepreneurship.

No competition in the market: if the product of the company is new then the company do not have to worry about the market competition because the product which they have launched is not there in the market eg. when Steve jobs launched personal computers at that time there was no competition in the market so they got a boost In the market and now they are well known as apple.

Will get a boost in the future: as we already know that who starts the business first will always get a boost in the market eg we know that paytm is the first one which started online recharge through new banking and debit card and now even if we compare this company from the other company like freerecharge and others paytm is one which is better in the market.

\section{New Production \& FACT FINDING TEChNIQUES}

There is a lot of ways to produce a new technique and new technique is the only one which is going to help to be a successful entrepreneurs which the help of new technique we can easily get a better position in the market as well as in any industry. And after this we have to observe the market and the value of our product in the market with the help of this we can say that we can new production technique is important.

For the study of the system the user are the analyst must collect the facts and also the required information. The facts when are expressed in terms of quantitatively than they are known as data. Any project will succeed depending on how much accurate is the data being collected and the accurate data can be collected with the help of different methods. This methods are termed as fact finding techniques. The user can use more than one techniques in order to verify the accuracy of the data. The different types of methods are as follows:

\section{A. Interview}

It is a technique where the information is being generated from many people. Only skilful users can use this type of technique. In this technique the user conducts a face to face interview and records their view and responses. The interviewer or the user must have the plan in advance to what type of questions would they want to ask to the people. The time and place must be chosen so that it is comfortable for the interviewee. In this method the information which are collected are most of the time accurate. This methods is also useful for separating the areas having doubts and also helps in discussing the problems in future. There are two types of interview and they are structured interview and unstructured interview.

\section{B. Questionnaire}

It is the technique that can be used only by the skilful analyst. It can be generated from different people. The questionnaire will consist series of questions which will be arranged in logical manner based on the data to be collected. Mostly the are always simple and its up to the point. This method is very useful for gathering information especially for the people who are in different places [12]. This set of questions can be sent by mail through internet or by post. It is one of the cheapest techniques for fact finding.

\section{Record viewing}

Record viewing is one of the important techniques for it helps the analyst or the user to extract the important information's about the system or in the organization. The information may be published in newspapers, documents etc.

\section{Observations}

It is also one important technique used in fact finding. For this process an user or the analyst must visit the organization or the system. It is generally a practical process. The analyst must observe and understand the flowing of documents and also how the system works. The analyst must have the clear idea about the area he or she is observing and the important points must be highlighted. Sometimes the analyst may also observe some negative or unwanted things during the process which may cause delay in the implementation of new system.

\section{The Procedure of THE SySTEM ANALYSIS}

The procedure of the system analysis are divided as

\section{A. Research}

For gather all necessary information related to the present system works also collect all similar systems from the other organizations.

\section{B. Data Analysis}

To investigate whole working procedure of the present system and identifying current issues related with it. Identifying all the inputs, outputs and it analysis assist the designer to understand the target system working methodology which is very helpful for system modification and modernizations . It is based on three parameters analysis (i) system inputs, (ii) process and (iii) output from the system. Importance is given on actions and interactions among the 
different subsystems and their involvement to achieve desirer target.

\section{Design and Development Process}

The problems associated with existing system are determined in the previous steps, the analyst can initiate preparation how the proposed system will fix those difficulties and try to convert difficulties into opportunity. The systems analyst prepared a register of task and requirements list with details specifications required for the propose module. Here 'requirements' may be desire targets or aims, which are known as Requirements Specifications [13]. The analyst may require new hardware and software. The analyst may require special input devices like scanners, barcode readers, card readers etc. and also any special output device. Based on their decision type the custom-written software or off-the-shelf software like ready-made type software may be procedures [6]. Off-the-shelf software is developed for use by a wide range of user and may not be system dependent, basically general-purpose and trusted and more reliable for the reason that most troubles will have been faced among the several end-users. Lots of the support lots of help and support offered due to many users are using it [14]. Custom-written software or dedicated software is developing particularly for one customer hence it become very expensive but provides exactly what the analyst wants. Due to only one user, so very little help is available.

\section{Testing}

Once the desire modifications in the system have been made, it needed to be systematically tested and verified with the benchmark results. A test plan is generally formed and written as wish list for the target system or module is being design. The proposed test plan must include all information of each single point that required to be provided to understand about the modified system. For example data be entered and saved properly and may reproduce when required. Facility option may be provide for manage different testing procedure. When something erroneous, does an error message appear or no etc. specified test very precisely. Test plans for the proposed system are may be contained every detailed, and contain many contains a series of tests. A typical test would contain details about tested parameters, set of the test data for used, test conditions and expected outcome from the experiments. Selected data for testing purpose whole system need to check if it the system doesn't failed and created system works as per expectation or not.

\section{E. Documentations}

Creating documents mainly used to describe how the new systems use or new modules, and its working procedure. There are generally two types of common manual or documentation techniques which are needed to produce when construct a new module: (i) user documentation or user manual and (ii) technical documentation or specification sheet.
Technical documentation usually includes, (i) all details of the required hardwires and software for the system, (ii) flowcharts and or algorithms describing how the system works and how data is processed methodology along with details of expected inputs and complete data structures.

\section{F. Implementation}

Implementation is basically replacing the present system with the new system. It is essential to know accurately how the organization works without knowing its sub modules or sub sections some Evaluation or checking is that the new system meets all expectations. It may be parallel implementation [6]. It may provides a structure for imagine the organizational and ecological issue which work on a sub system or as a whole system. When a computer and other automatic machine is introduced into an organization, different role of the existing workers may affected as a result both the client and organization suffered [15]. Among the optimized peoples are change and improved routine and a sensation of accomplishment with some additional information to enhance their job roles. Among the unexpected penalty might be a possible like lose their employment, decrease the spirits of recruits due to back of participation and a feeling of demands by end users and organizations due to their lack of technical knowledge to handle the automatic machine or may be for computer illiteracy. The system analyst's responsibility is to take out such kinds of doubts and try to make the whole modernizations successful.

\section{$G$. Repeat the process again and again}

The process should be repeated again and again until the required outcomes are not come.

\section{CONCLUSION}

Basically the most important point in the innovation is to create a totally new product the new product could be anything can exploit an established technology or it can be a totally new technology which never have been launched into the market. The new product may pursue in a very good manner or it could be the one which is just a modification in the existing product. With the help of new product we can earn a lot of product as well as we can establish own company.

\section{REFERENCES}

[1] F. Milano, "An Open Source Power System Analysis Toolbox," IEEE Transactions on Power Systems, vol. 20, no. 3, pp. 1199-1206, Aug 2005.

[2] R. Sanchez and J. T. Mahoney, "Modularity, Flexibility, and Knowledge Management in Product and 
Organization Design," Strategic Management Journal , vol. 17, no. S2, pp. 63-76, 1996.

[3] F. James and M. Roos, "Minuit - a System for Function Minimization and Analysis of the Parameter Errors And Correlations," Computer Physics Communications, vol. 10, no. 6, p. 343-367, Decembe 1975.

[4] R. E. Kalman and J. E. Bertram, "Control System Analysis and Design Via the "Second Method" of Lyapunov: I-Continuous-Time Systems," Journal of Basic Engineering, vol. 82, no. 2, pp. 371-393, 01 Jun 1960.

[5] A. Ferreiraa and D. Otleyb, "The Design and use of Performance Management Systems: An Extended Framework for Analysis," Management Accounting Research, vol. 20, no. 4, p. 263-282, Decembe 2009.

[6] G. Granelli, M. Montagna, F. Zanellini, P. Bresesti and R. Vailati, "A Genetic Algorithm-Based Procedure To Optimize System Topology Against Parallel Flows," IEEE Transactions on Power Systems, vol. 21, no. 1, pp. 333 - 340, Feb 2006.

[7] K. Mukherjee, "The Psychology of the Successful Entrepreneur," International Journal of Advanced Engineering and Management, vol. 1, no. 1, pp. 25-32, 2016.

[8] M. Mukherjee, "Entrepreneurial Judgment and Analysis for Successful Strategy Implementation," International Journal of Advanced Engineering and Management, vol. 2, no. 1, pp. 1-8, 2017.

[9] M. Dorigo and L. Gambardella, “Ant Colony System: A Cooperative Learning Approach to The Traveling Salesman Problem," IEEE Transactions on Evolutionary Computation, vol. 1, no. 1, pp. 53 - 66, Apr 1997.
[10] A. Bergeka, S. Jacobssonb, B. Carlsson, S. Lindmark and A. Rickne, "Analyzing The Functional Dynamics Of Technological Innovation Systems: A scheme of Analysis," Research Policy, vol. 37, no. 3, pp. 407-429, April 2008.

[11] C. Edquist, "Design of Innovation Policy Through Diagnostic Analysis: Identification of Systemic Problems (or Failures)," Industrial and Corporate Change vol. 20, no. 6, pp. 1725-1753, Dcember 2011.

[12] R. Simons, "Accounting Control Systems and Business Strategy: An Empirical Analysis," Accounting, Organizations and Society, vol. 12, no. 4, pp. 357-374, 1987.

[13] T. Browning, "Applying The Design Structure Matrix to System Decomposition and Integration Problems: A Review And New Directions," IEEE Transactions on Engineering Management, vol. 48, no. 3, pp. 292-306, Aug 2001.

[14] A. K. Chopra and R. K. Goel, "A Modal Pushover Analysis Procedure for Estimating Seismic Demands for Buildings," Earthquake Engineering \& Structural Dynamics, vol. 31, no. 3, pp. 561-582, 2002 .

[15] R. K. Woolthuisa, M. Lankhuizenb and V. Gilsingc, “A System Failure Framework for Innovation Policy Design," Technovation, vol. 25, no. 6, pp. 609-619, June 2005 . 